\title{
THE MEAN INEQUALITY OF RANDOM VARIABLES
}

\author{
MINGJIN WANG
}

Abstract. In this paper, we prove an inequality about random variables. The inequality extends and compliments some existing results in the literature on Kantorovich type inequalities.

Mathematics subject classification (2000): Primary 60E15, 26D20.

Key words and phrases: inequality, arithmetic mean, geometric mean, expectation.

\section{REFERENCES}

[1] Hardy, G. H., Littlewood, J. E. AND Polya, G(1934,1952) Inequalities, $1^{\text {st }}$, ed. $2^{\text {nd }}$, ed. Cambridge Univ. Press. London. 